\title{
High levels of SARS-CoV-2-specific T cells with restricted functionality in severe courses of COVID-19
}

David Schub, ${ }^{1}$ Verena Klemis, ${ }^{1}$ Sophie Schneitler, ${ }^{2}$ Janine Mihm, ${ }^{3}$ Philipp M. Lepper, ${ }^{4}$ Heinrike Wilkens, ${ }^{4}$ Robert Bals, ${ }^{4}$ Hermann Eichler, ${ }^{5}$ Barbara C. Gärtner, ${ }^{2}$ Sören L. Becker, ${ }^{2}$ Urban Sester, ${ }^{3}$ Martina Sester, ${ }^{1}$ and Tina Schmidt ${ }^{1}$

'Department of Transplant and Infection Immunology, ${ }^{2}$ Institute of Medical Microbiology and Hygiene, ${ }^{3}$ Department of Internal Medicine IV, ${ }^{4}$ Department of Internal Medicine V, and ${ }^{5}$ Institute of Clinical Hemostaseology and Transfusion Medicine, Saarland University, Homburg, Germany.

BACKGROUND. Patients infected with severe acute respiratory syndrome coronavirus 2 (SARSCoV-2) differ in the severity of disease. We hypothesized that characteristics of SARS-CoV-2specific immunity correlate with disease severity.

METHODS. In this study, SARS-CoV-2-specific T cells and antibodies were characterized in uninfected controls and patients with different coronavirus disease 2019 (COVID-19) disease severity. SARS-CoV-2-specific T cells were flow cytometrically quantified after stimulation with SARS-CoV-2 peptide pools and analyzed for expression of cytokines (IFN- $\gamma$, IL-2, and TNF- $\alpha$ ) and markers for activation, proliferation, and functional anergy. SARS-CoV-2-specific IgC and IgA antibodies were quantified using ELISA. Moreover, global characteristics of lymphocyte subpopulations were compared between patient groups and uninfected controls.

RESULTS. Despite severe lymphopenia affecting all major lymphocyte subpopulations, patients with severe disease mounted significantly higher levels of SARS-CoV-2-specific T cells as compared with convalescent individuals. SARS-CoV-2-specific CD4 ${ }^{+} \mathrm{T}$ cells dominated over $\mathrm{CD8}{ }^{+} \mathrm{T}$ cells and closely correlated with the number of plasmablasts and SARS-CoV-2-specific IgA and IgC levels. Unlike in convalescent patients, SARS-CoV-2-specific T cells in patients with severe disease showed marked alterations in phenotypical and functional properties, which also extended to $\mathrm{CD4} 4^{+}$and $\mathrm{CD} 8^{+}$ $\mathrm{T}$ cells in general.

CONCLUSION. Given the strong induction of specific immunity to control viral replication in patients with severe disease, the functionally altered characteristics may result from the need for contraction of specific and general immunity to counteract excessive immunopathology in the lung.

FUNDING. The study was supported by institutional funds to MS and in part by grants of Saarland University, the State of Saarland, and the Rolf M. Schwiete Stiftung.

Conflict of interest: The authors have declared that no conflict of interest exists.

Copyright: (c) 2020, Schub et al. This is an open access article published under the terms of the Creative Commons Attribution 4.0 International License.

Submitted: July 13, 2020 Accepted: September 16, 2020 Published: September 16, 2020

Reference information: /CI Insight. 2020;5(20):e142167. https://doi.org/10.1172/jci. insight.142167.

\section{Introduction}

Coronavirus disease 2019 (COVID-19), the disease caused by severe acute respiratory syndrome coronavirus 2 (SARS-CoV-2), can be asymptomatic or mild but also includes severe disease manifestations, such as acute respiratory distress syndrome, which can lead to multi-organ failure and death despite intensive medical treatment. The mortality rate is particularly high in older individuals and in patients with preexisting lung, heart, or immunodeficiency diseases $(1,2)$.

Studies have shown that SARS-CoV-2 infection causes global changes in cellular immunity, mainly characterized by lymphopenia, skewed distribution of $\mathrm{T}$ cell subpopulations, and high plasma concentrations of proinflammatory cytokines $(2,3)$. In addition, $\mathrm{T}$ cell functionality appears to be altered as shown by impaired expression of IFN- $\gamma$ (4-6). So far, mainly nonspecific general changes in the number and functionality of blood cells have been described, whereas specific T cell immunity directed against SARS-CoV-2 has as yet not been studied as extensively (7-11), especially in patients with different disease severity. 
It seems reasonable to suggest that the individual course of a SARS-CoV-2 infection depends on the induction and functionality of the adaptive immunity including both antibodies and $\mathrm{T}$ cells. Seroconversion in patients with COVID-19 does not seem to be delayed, because SARS-CoV-2-specific IgM and IgA antibodies are induced early after the onset of symptoms after a median of 5 days, while the median time for IgG seroconversion is 14 days (12-14). Thus far, it remains to be elucidated whether patients with different disease manifestations differ in the levels and functionality of SARS-CoV-2-specific T cells or antibodies. We have previously shown that symptomatic infections with persistent pathogens are associated with alterations in pathogen-specific $\mathrm{T}$ cell levels and impaired functionality as compared with individuals with successful immune control (15-20).

Based on these observations, we hypothesized that T cells induced against SARS-CoV-2 may differ in quantity and functionality depending on the severity of symptoms of COVID-19. Moreover, we hypothesized that antigen-specific T cell characteristics may affect B cell subpopulations and SARS-CoV-2-specific antibodies. We therefore recruited 2 groups of patients who were similar in the time elapsed since onset of clinical symptoms. One group included hospitalized patients with a severe course of disease, whereas a second group comprised convalescent individuals who had mild disease manifestations and who completely recovered from SARS-CoV-2-related symptoms mainly in an outpatient setting.

\section{Results}

Study population. In this study, 50 patients with COVID-19 were included at a median of 42.5 (IQR 16.5) days after onset of symptoms. Among those, 14 were critically ill patients ( $64.3 \pm 8.2$ years) hospitalized in the intensive care unit ("ICU patients"), whereas 36 individuals (42.2 \pm 13.6 years) had recovered from COVID-19 in an outpatient setting ("convalescent patients") with no or mild remaining symptoms at the time of analysis: cough $(n=3)$, rhinitis $(n=2)$, myalgia $(n=2)$, and anosmia $(n=7)$. Both groups did not differ in the median time after onset of symptoms at the time of analysis (ICU patients: 40.0 [IQR 15.0] days; convalescent patients: 43.5 [IQR 16.5]) days; $P=0.37$ ). Ten individuals without evidence for SARSCoV-2 infection were recruited as negative controls (48.1 \pm 11.4 years). The demographic and clinical characteristics of patients and controls are shown in Table 1. As expected, ICU patients were significantly older as compared with the other groups $(P<0.0001)$. Cardiovascular disease $(10 / 14$ ICU patients $)$ and metabolic diseases (7/14 ICU patients, especially obesity) were the most common comorbidities in ICU patients. Median time from symptom onset to hospital admission was 5 (IQR 5.5) days and 7 (IQR 6) days to ICU admission. Eleven patients were mechanically ventilated, of which 7 were additionally treated with extracorporeal membrane oxygenation, and 7 received renal replacement therapy. Therapeutic drug regimens included hydroxychloroquine and azithromycin in 11 cases, 1 patient received tocilizumab, 1 patient received icatibant, and 2 patients underwent a 3-day course of high-dose steroid treatment. Viral load determinations were not performed for all patients on a regular schedule. Information on the duration of viral encounter was given in 8 patients, where at least 2 subsequent test results documented a median of up to 19.5 days (range 6-34 days) of continuous PCR positivity. Three patients died 8, 15, and 16 days after analysis, of which 1 still was SARS-CoV-2 PCR positive. Twelve out of 14 ICU patients became SARS-CoV-2 PCR negative during the hospital stay, with 11 patients known to have a first negative test result at least 8 days before the blood sampling (median 9 days; range 8-28 days). PCR results on follow-up were not available for 1 patient who was readmitted to the primary care hospital after the end of mechanical ventilation and clinical stabilization. SARS-CoV-2 PCR was performed in 33/36 convalescent patients after quarantine, and all tests were negative.

Altered counts of leukocytes and lymphocyte subpopulations in patients with severe COVID-19. Leukocyte numbers and differential white blood cell counts showed substantial differences between ICU patients and convalescent individuals, with increased levels of neutrophils and severe lymphopenia as the most prominent findings (Table 1). In contrast, convalescent individuals had similar levels as controls (Table 1). A more detailed analysis of lymphocytes and their subpopulations was performed from whole blood using flow cytometry. Absolute cell counts were calculated based on differential blood counts. As shown in Figure 1, lymphopenia affected all major lymphocyte subpopulations, such as NK cells, B cells, and T cells, including CD4 ${ }^{+}$and CD8 ${ }^{+} \mathrm{T}$ cells and Tregs.

Significantly higher percentages of SARS-CoV-2-specific T cells in patients with severe COVID-19. To identify specific immunity against SARS-CoV-2, whole-blood samples were stimulated with overlapping peptide pools covering the major SARS-CoV-2 structural spike protein (spike $\mathrm{N}$ and C-terminal peptide sets, respectively), the nucleocapsid (NCAP) protein, the membrane protein VME1, and the envelope small membrane protein VEMP. 
Table 1. Demographic and clinical characteristics of the study population

\begin{tabular}{|c|c|c|c|c|}
\hline & \multicolumn{4}{|c|}{ SARS-CoV-2 infected } \\
\hline & Controls & ICU patients & Convalescent $^{A}$ & $P$ value \\
\hline Number & $n=10$ & $n=14$ & $n=36$ & NA \\
\hline Years of age (mean \pm SD) & $48.1 \pm 11.4$ & $64.3 \pm 8.2$ & $42.2 \pm 13.6^{B}$ & $<0.0001^{\mathrm{C}}$ \\
\hline Sex (\% females) & $7 / 10(70 \%)$ & $1 / 14(7.1 \%)$ & $17 / 34(50 \%)^{B}$ & $0.004^{D}$ \\
\hline $\begin{array}{l}\text { Days since onset of } \\
\text { symptoms, median (IQR) }\end{array}$ & NA & $40(15)$ & $43.5(16.5)$ & $0.37^{\mathrm{E}}$ \\
\hline $\begin{array}{l}\text { Days from symptoms to } \\
\text { hospitalization (mean } \pm \text { SD) }\end{array}$ & NA & $5.3 \pm 3.8$ & NA & NA \\
\hline $\begin{array}{l}\text { Days from symptoms to ICU } \\
\text { (mean } \pm \mathrm{SD} \text { ) }\end{array}$ & NA & $7.8 \pm 3.3$ & NA & NA \\
\hline $\begin{array}{l}\text { Leukocytes (cells/ } \mu \mathrm{L} \text { ), } \\
\text { median (IQR) }\end{array}$ & 6940 (3085) & 9500 (9350) & 6615 (2690) & $0.0005^{F}$ \\
\hline $\begin{array}{l}\text { Granulocytes (cells/ } \mu \mathrm{L} \text { ), } \\
\text { median (IQQR) }\end{array}$ & $4043(1840)$ & 7934 (8511) & $4575(2453)$ & $0.0004^{F}$ \\
\hline $\begin{array}{l}\text { Monocytes (cells/ } \mu \mathrm{L} \text { ), } \\
\text { median (IQRR) }\end{array}$ & 589 (309) & $365(620)$ & $592(226)$ & $0.323^{F}$ \\
\hline $\begin{array}{l}\text { Lymphocytes (cells/ } \mu \mathrm{L} \text { ), } \\
\text { median (IQR) }\end{array}$ & 2381 (1349) & 910 (458) & 2307 (728) & $<0.0001^{F}$ \\
\hline \multicolumn{5}{|c|}{$\begin{array}{l}\text { All individuals were Caucasian. }{ }^{A} \text { Differential blood counts were available for } 21 / 36 \text { convalescent individuals. }{ }^{\mathrm{B}} \text { Two } \\
\text { convalescent individuals were included without knowledge of age, sex, and ethnicity. }{ }^{\mathrm{C} O n e-w a y ~ A N O V A} .{ }^{\mathrm{D}} \chi^{2} \text { test. }{ }^{\mathrm{E}} \mathrm{Mann}- \\
\text { Whitney } U \text { test. }{ }^{\mathrm{F}} \text { Kruskal-Wallis test. ICU, intensive care unit. }\end{array}$} \\
\hline
\end{tabular}

Stimulation was carried out for 6 hours, and antigen-specific T cells were identified by intracellular staining of cytokines (IFN- $\gamma$, IL-2, and TNF- $\alpha$ ) among activated $\mathrm{CD} 69^{+} \mathrm{CD} 4^{+}$and CD $8^{+}$T cells. Stimulation with Staphylococcus aureus enterotoxin B (SEB) allowed assessment of polyclonal T cell responses. DMSO was used to control for background reactivity, which was subtracted from specific stimulations. To characterize response patterns of stimulation-induced $\mathrm{CD}^{+}$and $\mathrm{CD} 8^{+} \mathrm{T}$ cells toward the various peptide pools, we first focused on IFN- $\gamma^{+} \mathrm{T}$ cells because IFN- $\gamma$ is the most specific and readily induced in T cells toward a variety of clinically relevant pathogens $(16,17,21)$. A typical set of contour plots from a hospitalized patient illustrating induction of SARS-CoV-2specific $\mathrm{T}$ cell reactivity among $\mathrm{CD} 4^{+}$and $\mathrm{CD} 8^{+} \mathrm{T}$ cells is shown in Figure $2 \mathrm{~A}$. When analyzing all individuals, $\mathrm{CD}^{+} \mathrm{T}$ cell frequencies were highest after stimulation with spike $\mathrm{N}$ and VME1, followed by spike $\mathrm{C}$ and NCAP, whereas reactivity toward the smallest protein, VEMP, was largely absent. Antigen-specific CD8 ${ }^{+} \mathrm{T}$ cell levels were generally lower, with the most pronounced reactivity after stimulation with spike N and NCAP. In contrast, spike C, VME1, or VEMP elicited only modest or no reactivity with no difference between infected and noninfected groups (Figure $2 \mathrm{~B}$ ). When comparing antigen reactivity in the 3 groups, significantly higher levels of SARS-CoV-2-specific CD4 ${ }^{+} \mathrm{T}$ cells were found in both infected patient groups as compared with negative controls, who were largely nonresponsive (Figure $2 \mathrm{~B}$ ). A difference between infected and noninfected individuals was also observed for $\mathrm{CD} 8^{+} \mathrm{T}$ cells reacting toward spike $\mathrm{N}$ or NCAP, whereas $\mathrm{CD} 8^{+} \mathrm{T}$ cell reactivity toward the remaining peptide pools was equally low in both infected and noninfected groups (Figure $2 \mathrm{~B}$ ). Interestingly, among convalescent patients, individuals with lower respiratory symptoms, such as cough or dyspnea $(n=19)$, had significantly higher median levels of SARS-CoV-2-specific CD4 ${ }^{+} \mathrm{T}$ cells $(0.16 \%$, IQR $0.17 \%)$ than individuals without these symptoms ( $n=17 ; 0.08 \%$, IQR $0.127 \% ; P=0.015$; data not shown).

To obtain an estimate of the total levels of SARS-CoV-2-specific T cells in each group, SARS-CoV-2specific $\mathrm{T}$ cell frequencies toward the individual peptide pools were added up for each individual (Figure 2C). This showed that patients with a severe course had the highest levels of SARS-CoV-2-specific CD4 ${ }^{+} \mathrm{T}$ cells $(0.48 \%$, IQR $0.37 \%)$, which not only differed from negative controls $(0.01 \%$, IQR $0.01 \%)$ but also differed from convalescent individuals $(0.13 \%$, IQR $0.18 \% ; P<0.0001)$. This contrasts with polyclonal SEB-reactive $\mathrm{CD}^{+} \mathrm{T}$ cell frequencies, which were significantly lower in ICU patients $(1.77 \%$, IQR $1.76 \%)$ as compared with controls $(3.97 \%$, IQR $2.15 \%)$ or convalescent patients $(5.06 \%$, IQR $5.07 \%, P=0.0001$, Figure 2C). Likewise, total levels of SARS-CoV-2-specific $\mathrm{CD} 8^{+} \mathrm{T}$ cells were significantly higher in patients than in noninfected controls $(P=0.023)$, whereas the difference between ICU patients and convalescent patients did not reach statistical significance. Unlike in $\mathrm{CD}^{+} \mathrm{T}$ cells, SEB-reactive $\mathrm{CD} 8^{+} \mathrm{T}$ cell levels were similar among 

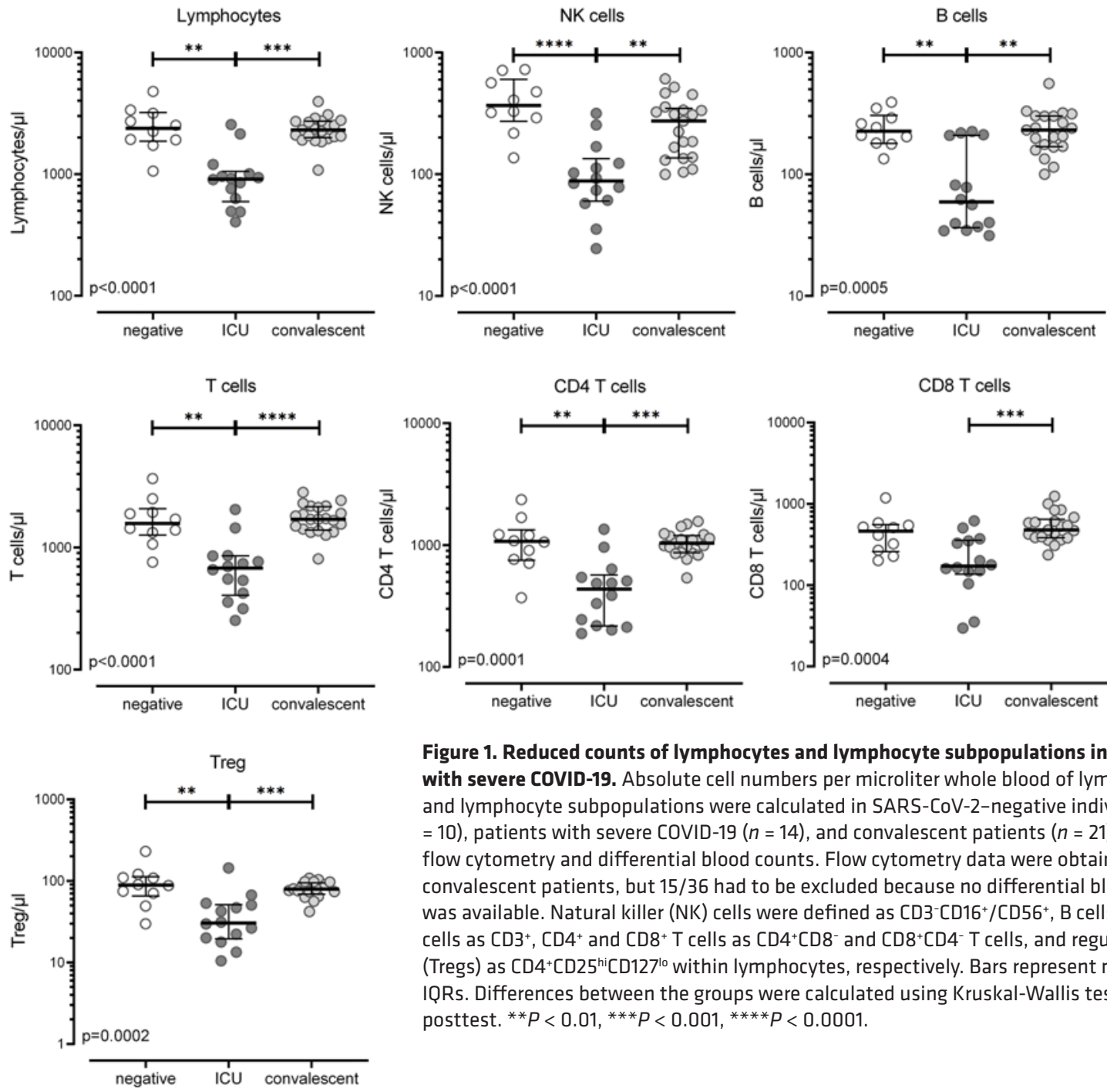

Figure 1. Reduced counts of lymphocytes and lymphocyte subpopulations in patients with severe COVID-19. Absolute cell numbers per microliter whole blood of lymphocytes and lymphocyte subpopulations were calculated in SARS-CoV-2-negative individuals ( $n$ $=10)$, patients with severe COVID-19 $(n=14)$, and convalescent patients $(n=21)$ based on flow cytometry and differential blood counts. Flow cytometry data were obtained from all convalescent patients, but $15 / 36$ had to be excluded because no differential blood count was available. Natural killer (NK) cells were defined as CD3-CD16 ${ }^{+} / \mathrm{CD}^{-} 6^{+}$, B cells as $\mathrm{CD}^{-} 9^{+}, \mathrm{T}$ cells as $\mathrm{CD}^{+}, \mathrm{CD}^{+}$and $\mathrm{CD} 8^{+} \mathrm{T}$ cells as $\mathrm{CD}^{+}{ }^{+} \mathrm{CD} 8^{-}$and $\mathrm{CD} 8^{+} \mathrm{CD} 4^{-} \mathrm{T}$ cells, and regulatory $\mathrm{T}$ cells (Tregs) as $\mathrm{CD} 4{ }^{+} \mathrm{CD} 25^{\text {hi }} \mathrm{CD} 127^{10}$ within lymphocytes, respectively. Bars represent medians with IQRs. Differences between the groups were calculated using Kruskal-Wallis test and Dunn's posttest. ${ }^{* *} P<0.01,{ }^{* *} P<0.001,{ }^{* * *} P<0.0001$.

the 3 groups $(P=0.244)$. SARS-CoV-2-specific $\mathrm{CD}^{+} \mathrm{T}$ cell levels inversely correlated with time since onset of clinical symptoms $(r=-0.37, P=0.01)$, whereas this was not significant for specific $\mathrm{CD} 4^{+} \mathrm{T}$ cells $(P=0.1$; Supplemental Figure 1; supplemental material available online with this article; https://doi.org/10.1172/ jci.insight.142167DS1). Taken together, despite strong lymphopenia affecting both $\mathrm{CD}^{+}$and $\mathrm{CD} 8^{+} \mathrm{T}$ cells, and lower levels of polyclonal SEB-reactive $\mathrm{CD} 4^{+} \mathrm{T}$ cells, patients with severe COVID-19 were capable of mounting high levels of SARS-CoV-2-specific T cells.

Restricted functionality of SARS-CoV-2-specific CD4 $4^{+}$T cells in patients with a severe course of COVID-19. To characterize the functionality of SARS-CoV-2-specific T cells in more detail, their cytokine expression profile regarding IFN- $\gamma$, IL-2, and TNF- $\alpha$ was analyzed using flow cytometry. Representative contour plots showing cytokine expression profiles after stimulation with the antigens are shown in Supplemental Figure 2. Boolean gating of activated $\mathrm{CD}^{2} 9^{+} \mathrm{T}$ cells resulted in assessment of 7 subpopulations of cells producing all 3 cytokines, 2 cytokines, or 1 cytokine only. As with results shown from IFN- $\gamma^{+}$subpopulations (Figure 2C), the total percentage of SARS-CoV-2-specific CD4 ${ }^{+} \mathrm{T}$ cells producing any of the 3 cytokines was also highest among ICU patients $(P<0.0001)$, with a trend also observed for specific $\mathrm{CD}^{+} \mathrm{T}$ cells $(P=0.055$, Supplemental Figure 3$)$. We then further characterized SARS-CoV-2-reactive $\mathrm{CD}^{+} \mathrm{T}$ cells for their cytokine expression profiles. All cytokine-positive cells were set to $100 \%$ in each individual and assessed for distribution of the 7 subpopulations. As shown in Figure $3 \mathrm{~A}$, the percentage of multifunctional, SARS-CoV-2-specific $\mathrm{CD}^{+} \mathrm{T}$ cells with the ability to simultaneously produce all 3 cytokines was significantly lower in patients with severe courses as compared with convalescent individuals. This was associated with a concomitant higher expression of cells simultaneously producing IL-2 
A
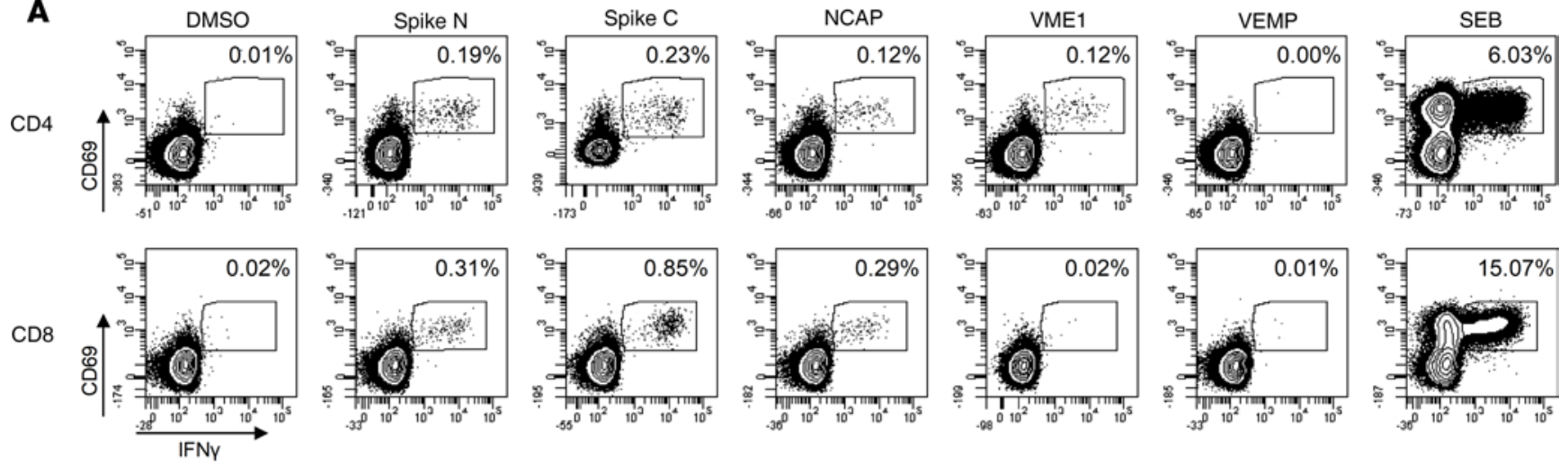

B
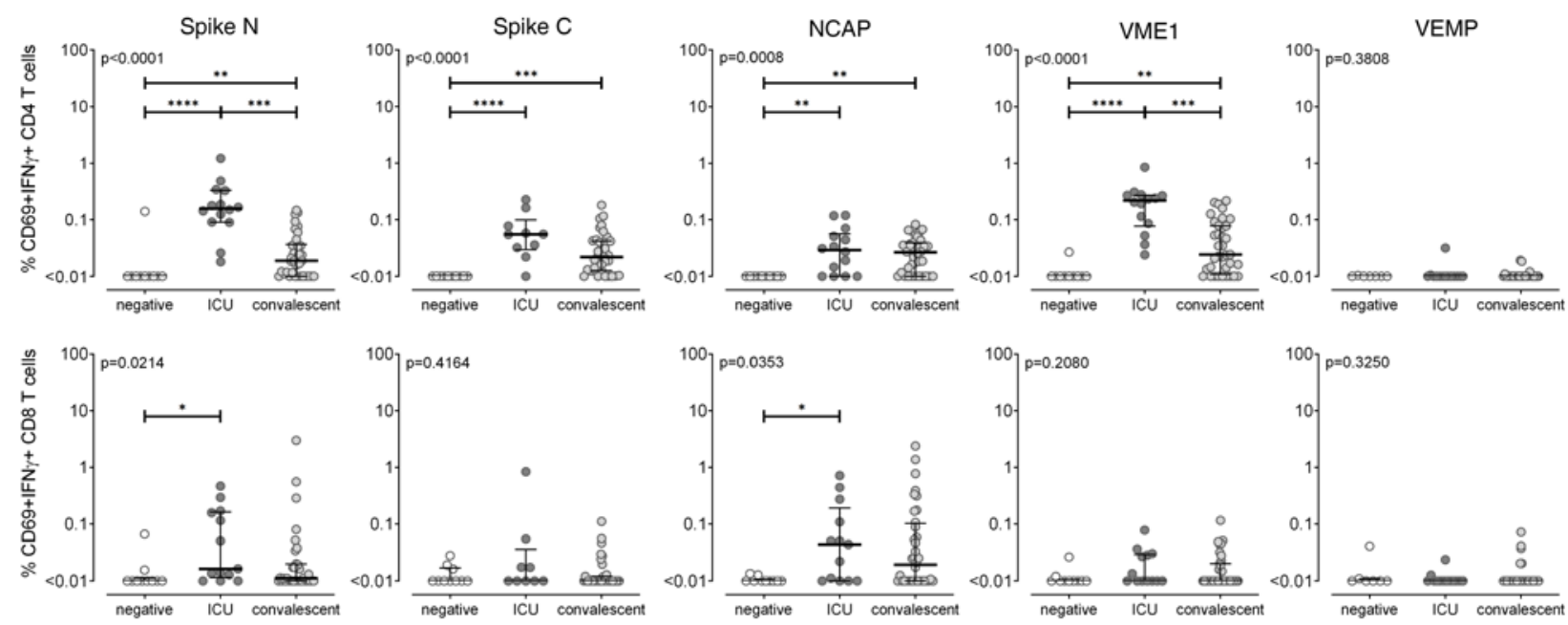

CD4
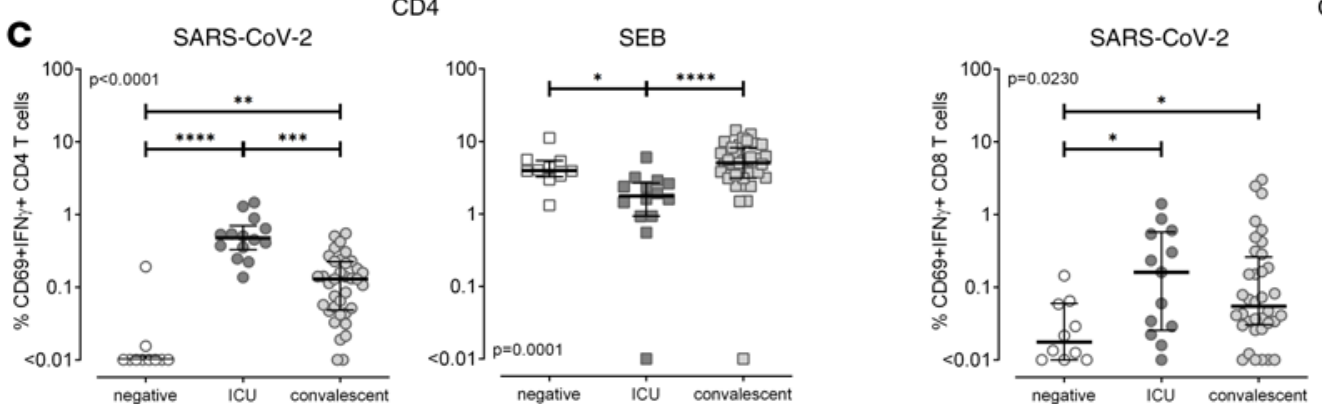

CD8

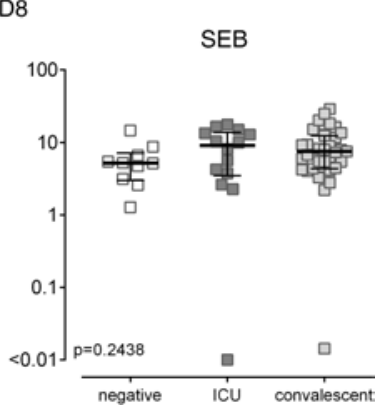

Figure 2. Increased percentages of SARS-CoV-2-specific T cells in patients with severe COVID-19. Whole-blood samples were stimulated with overlapping peptide pools spanning the SARS-CoV-2 spike protein (spike N, N-terminal; spike C, C-terminal), the NCAP protein, the membrane protein VME1, and the envelope small membrane protein VEMP. Stimulations with DMSO and SEB served as negative controls and polyclonal stimulus, respectively. (A) Contour plots illustrating specific immunity from a 56-year-old hospitalized patient are shown. Numbers indicate percentage of reactive (CD69+IFN- $\gamma^{+}$) cells within total $\mathrm{CD}^{+}$and $\mathrm{CD} 8^{+} \mathrm{T}$ cells. (B) Percentages of CD4+ and CD8+ $\mathrm{T}$ cells specific for the different SARS-CoV-2 antigens were compared between SARS-CoV-2negative individuals (negative, $n=10$ ), patients with severe COVID-19 (ICU, $n=14$ ), and convalescent patients $(n=36)$. (C) Total percentages of SARSCoV-2-specific (CD69+IFN- $\gamma^{+}$) T cells, determined by the sum of frequencies toward the individual peptide pools for each individual, and SEB-reactive T cell frequencies are compared between the 3 groups. Bars represent medians with IQRs. Differences between the groups were calculated using Kruskal-Wallis test and Dunn's posttest. ${ }^{*} P<0.05,{ }^{* *} P<0.01,{ }^{* * *} P<0.001,{ }^{* * *} P<0.0001$.

and TNF- $\alpha$. The same analysis was performed for cytokine-positive SEB-reactive CD4 ${ }^{+} \mathrm{T}$ cells. Both their magnitude (Supplemental Figure 3) and their cytokine profile were different from those of SARSCoV-2-specific cells. Nevertheless, the SEB-reactive and SARS-CoV-2-specific cytokine profiles exhibited similar differences between patients with severe disease and convalescent individuals (Figure 3A). In addition, the cytokine expression profile of SEB-reactive $\mathrm{CD} 4^{+} \mathrm{T}$ cells in convalescent individuals did not differ from SARS-CoV-2-noninfected controls (data not shown). This indicates that patients with 
severe disease have a restricted cytokine expression profile with lower percentages of multifunctional cells simultaneously producing all 3 cytokines. Unlike in convalescent patients, this restricted expression profile also extends to polyclonal $\mathrm{T}$ cells in general.

We also analyzed expression of cytotoxic T lymphocyte antigen 4 (CTLA-4) on SARS-CoV-2-specific and SEB-reactive $\mathrm{T}$ cells as phenotypical correlates of altered functionality commonly observed during active infections. This showed that SARS-CoV-2-specific CD4 ${ }^{+} \mathrm{T}$ cells from ICU patients had significantly higher expression levels of CTLA-4 than from convalescent patients $(P=0.035)$, which also held true for SEB-reactive $\mathrm{CD} 4{ }^{+} \mathrm{T}$ cells $(P<0.0001$, Figure $3 \mathrm{~B})$. Although the total number of patients with measurable SARS-CoV-2-reactive CD8 ${ }^{+} \mathrm{T}$ cells was lower, a similar trend was found for SARS-CoV-2-reactive or SEB-reactive $\mathrm{CD}^{+} \mathrm{T}$ cells (Figure 3B).

Finally, a subset of 10 SARS-CoV-2-infected patients (5 hospitalized, 5 convalescent patients) was studied to further characterize SARS-CoV-2-specific $\mathrm{CD}^{+}$and $\mathrm{CD}^{+} \mathrm{T}$ cells for expression of programmed cell death 1 (PD-1), Ki67, and granzyme B, with contour plots shown in Figure 3C. This analysis was restricted to samples with sufficient amounts of detectable SARS-CoV-2-specific T cells. PD-1 expression levels and the percentage of $\mathrm{Ki}^{+} 7^{+}$cells were higher on SARS-CoV-2-specific CD4 ${ }^{+}$ $\mathrm{T}$ cells than on polyclonal SEB-reactive $\mathrm{CD}^{+} \mathrm{T}$ cells. Likewise, although the number of individuals with sufficient numbers of SARS-CoV-2-specific $\mathrm{CD}^{+} \mathrm{T}$ cells was lower, some individuals had Ki67expressing $\mathrm{CD}^{+} \mathrm{T}$ cells; a large fraction of SARS-CoV-2-specific $\mathrm{CD} 8^{+} \mathrm{T}$ cells expressed granzyme $\mathrm{B}$, which was lower among SEB-reactive T cells (Figure 3C).

Altered characteristics of global $C D 4^{+}$and $C D 8^{+}$T cells in patients with severe COVID-19. Because cytokine expression patterns and CTLA-4 expression in patients with severe courses were altered in both SARSCoV-2-specific and SEB-reactive T cells, these alterations may also extend to T cells in general. To analyze bulk T cells in more detail, expression of CTLA-4 and PD-1, as well as Ki67 ${ }^{+}$cells, were analyzed directly from whole blood without prior stimulation, with representative contour plots shown in Figure 4A. As shown from MFIs in Figure 4B, both $\mathrm{CD}^{+}$and $\mathrm{CD} 8^{+} \mathrm{T}$ cells from ICU patients showed markedly increased expression of CTLA-4 and PD-1 as compared with controls, whereas respective expression in convalescent individuals was lower and similar to in controls. The same conclusion was reached if the percentage of CTLA-4- or PD-1-expressing cells was analyzed (Supplemental Figure 4). Interestingly, the percentage of recently proliferated $\mathrm{Ki}^{+} 7^{+} \mathrm{CD} 4^{+}$and $\mathrm{CD} 8^{+} \mathrm{T}$ cells was significantly higher in patients with a severe course as compared with controls and convalescent individuals.

Strong correlation of SARS-CoV-2-specific CD4 ${ }^{+}$T cell levels with specific IgG and IgA antibodies and plasmablasts. To comparatively analyze cellular and humoral immunity against SARS-CoV-2, specific IgA and IgG antibodies were determined using ELISA. As shown in Figure 5A, all individuals with severe courses were positive for SARS-CoV-2-specific IgG and IgA. Interestingly, their levels were significantly higher than those of convalescent individuals, among whom only 83\% (30/36 patients) had positive IgG and $69 \%$ (25/36 patients) had IgA above the detection limit. Intermediate IgA and IgG titers were found in 2 individuals each. SARS-CoV-2-negative controls did not show any specific IgG or IgA. In line with the role of $\mathrm{CD}^{+} \mathrm{T}$ cells in providing help for induction of humoral immunity, the percentage of SARS-CoV-2specific $\mathrm{CD}^{+} \mathrm{T}$ cells showed a significant correlation with both specific IgG $(r=0.77, P<0.0001)$ and $\operatorname{IgA}$ antibodies $(r=0.67, P<0.0001)$, whereas no correlation was observed with specific $\mathrm{CD} 8^{+} \mathrm{T}$ cells $(P=0.78$ for IgG; $P=0.52$ for IgA, Figure 5B). To elucidate whether the observed differences in specific antibody levels were related to differences in B cells among the groups, we analyzed CD19+ $\mathrm{B}$ cell subpopulations by their expression of IgD and CD27, with contour plots of a 64-year-old hospitalized patient shown in Figure $5 \mathrm{C}$. As with B cell lymphopenia in general (Figure 1), the numbers of naive $\left(\operatorname{IgD}^{+} \mathrm{CD} 27^{-}\right)$, non-switched memory $\left(\operatorname{IgD}{ }^{+} \mathrm{CD} 27^{+}\right)$, and switched memory B cells $\left(\operatorname{IgD}-\mathrm{CD} 27^{+}\right)$were significantly lower in patients with a severe course (Figure 5C). Interestingly, however, the number of plasmablasts, which were identified as $\mathrm{CD} 38^{+}$switched memory B cells, was significantly higher than in controls or convalescent patients. In line with the central role of plasmablasts in initiating antibody production, their numbers showed a strong correlation with both $\operatorname{IgG}(r=0.53, P=0.0014)$ and IgA antibody levels $(r=0.54, P=0.0013$, Figure $5 \mathrm{D})$.

\section{Discussion}

Manifestation of SARS-CoV-2 infections may range from asymptomatic infections or mild symptoms to severe courses of disease with a high risk of fatal outcome (2). In this study, we show that SARS-CoV-2specific immunological characteristics in patients with a severe course are clearly distinct from infected 
A
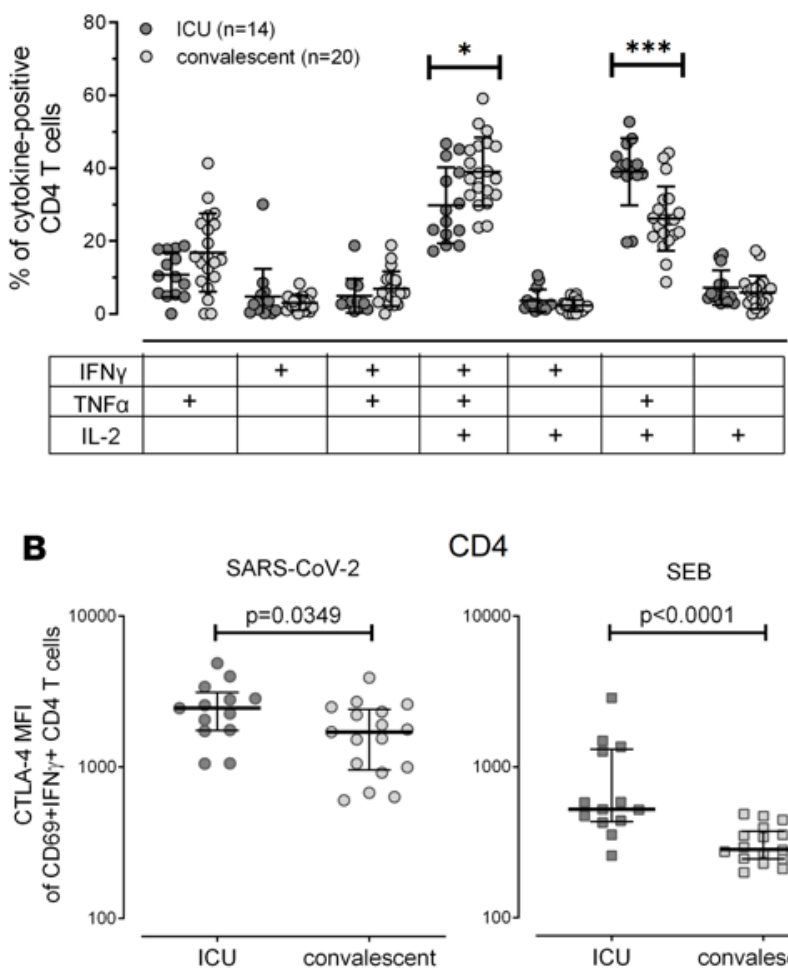

CD4

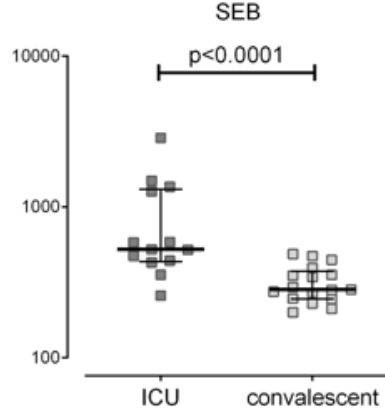

C

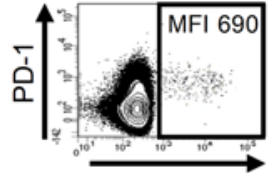

IFNY

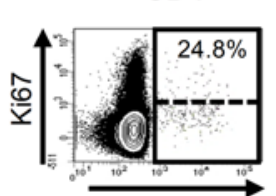

IFNY

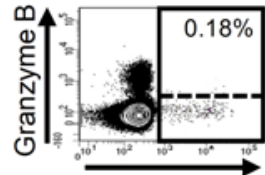

IFNY
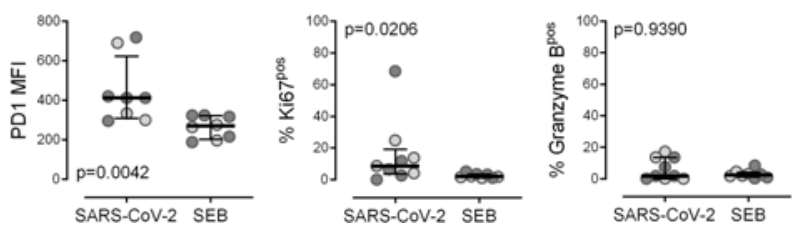

SEB

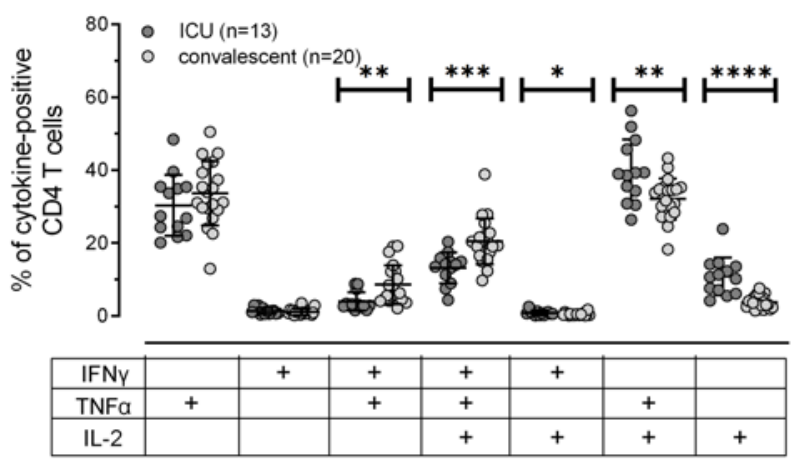

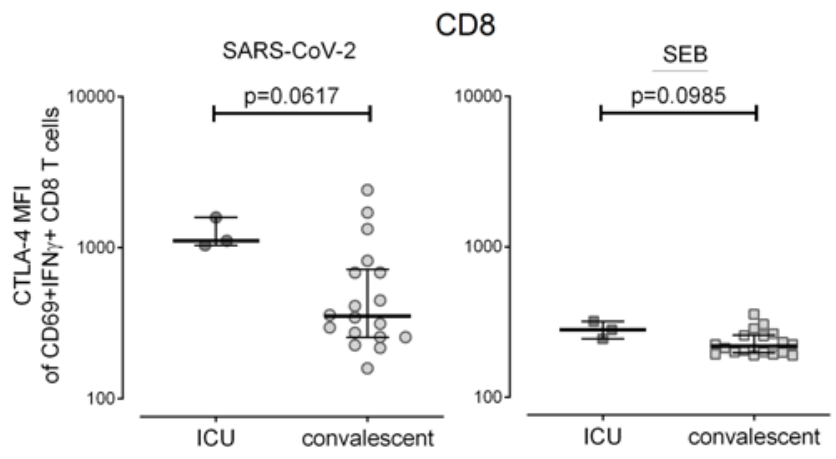

Figure 3. Altered cytokine profiles and characteristics of SARS-CoV-2-specific T cells in patients with a severe course of COVID-19. Expression patterns of SARS-CoV-2-specific T cells were determined from combined T cells reacting to the individual peptide pools for each individual. (A) SARS-CoV-2specific and SEB-reactive CD4+ T cells were divided into 7 subpopulations according to their expression of the cytokines IFN- $\gamma$, IL-2, and TNF- $\alpha$. Distribution of these subgroups was compared between ICU patients and convalescent patients. To ensure robust statistical analysis, cytokine profiling was restricted to CD4+ $T$ cells and to all samples with at least 35 measurable CD69+IFN- $\gamma^{+}$cells (all ICU patients and 20 convalescent patients). (B) CTLA-4 expression of SARS-CoV-2-specific and SEB-reactive CD4+ and CD8 ${ }^{+} \mathrm{T}$ cells was compared between ICU patients and convalescent patients. Analysis was restricted to individuals with sufficient SARS-CoV-2-specific immunity, i.e., where the total number of measurable CD69+IFN- $\gamma^{+}$cells reached at least 20 cells ( $n=13$ and 3 ICU patients and 17 and 18 convalescent patients for CD4+ and CD8 ${ }^{+}$T cells, respectively). (C) In a subgroup of 10 patient samples (5 ICU patients and 5 convalescent patients), where a larger sample volume for in vitro stimulations was available, expression of PD-1, Ki67, and granzyme B of SARS-CoV-2-specific and SEB-reactive CD4 ${ }^{+}$and $C D 8^{+} T$ cells was analyzed. Overlaid contour plots (built using BD FACSDiva 8) of samples from a 31-yearold convalescent patient stimulated with SARS-CoV-2 antigens are shown in the upper panel. PD-1 MFI was analyzed from all stimulatory reactions with at least 20 CD69+IFN- $\gamma^{+}$cells ( $n=8$ and 4 for CD4 ${ }^{+}$and CD8 ${ }^{+}$T cells, respectively). Analysis of intranuclear presence of Ki67 (\%Ki67 ${ }^{+}$) and expression of granzyme B (\%granzyme $\left.B^{+}\right)$was restricted to samples with at least 20 specific $\mathrm{CD}^{+}\left(n=8\right.$ for SARS-CoV-2 and $n=7$ for SEB) or CD8 ${ }^{+}$T cells $(n=4)$, respectively. ICU patients are depicted by dark symbols and convalescent patients by light symbols. Bar charts in $\mathbf{A}$ represent mean and SD, and differences between the 2 groups were assessed using unpaired 2-tailed $t$ test. Bars in $\mathbf{B}$ and $\mathbf{C}$ represent medians with IQRs. Differences between the groups were calculated using Mann-Whitney $U$ test. ${ }^{*} P<0.05$, ${ }^{* *} P<0.01$, ${ }^{* *} P<0.001$, ${ }^{* * *} P<0.0001$. MFI, median fluorescence intensity. 
A

CTLA-4

CD4

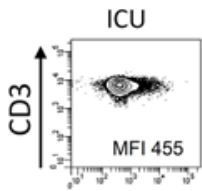

CD8

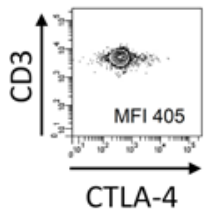

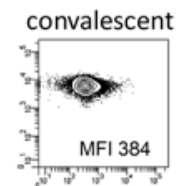

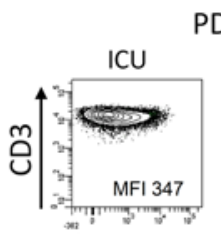

PD-1
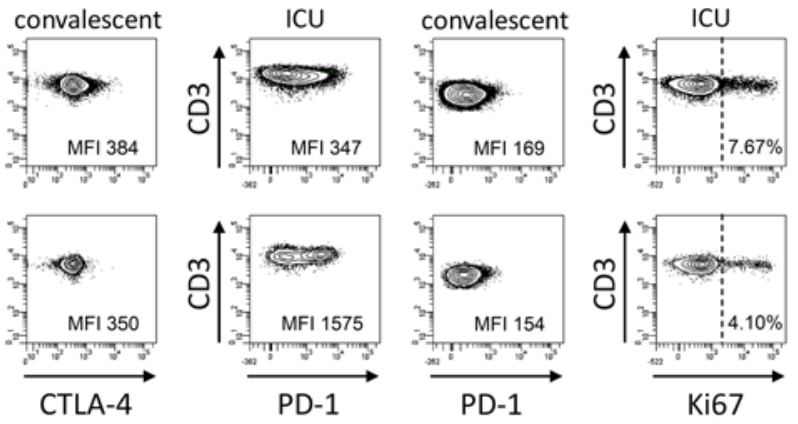

Ki67

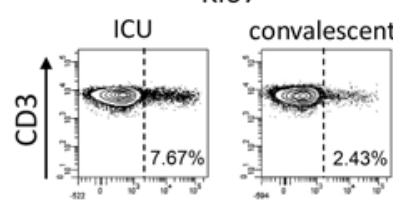

CTLA-4
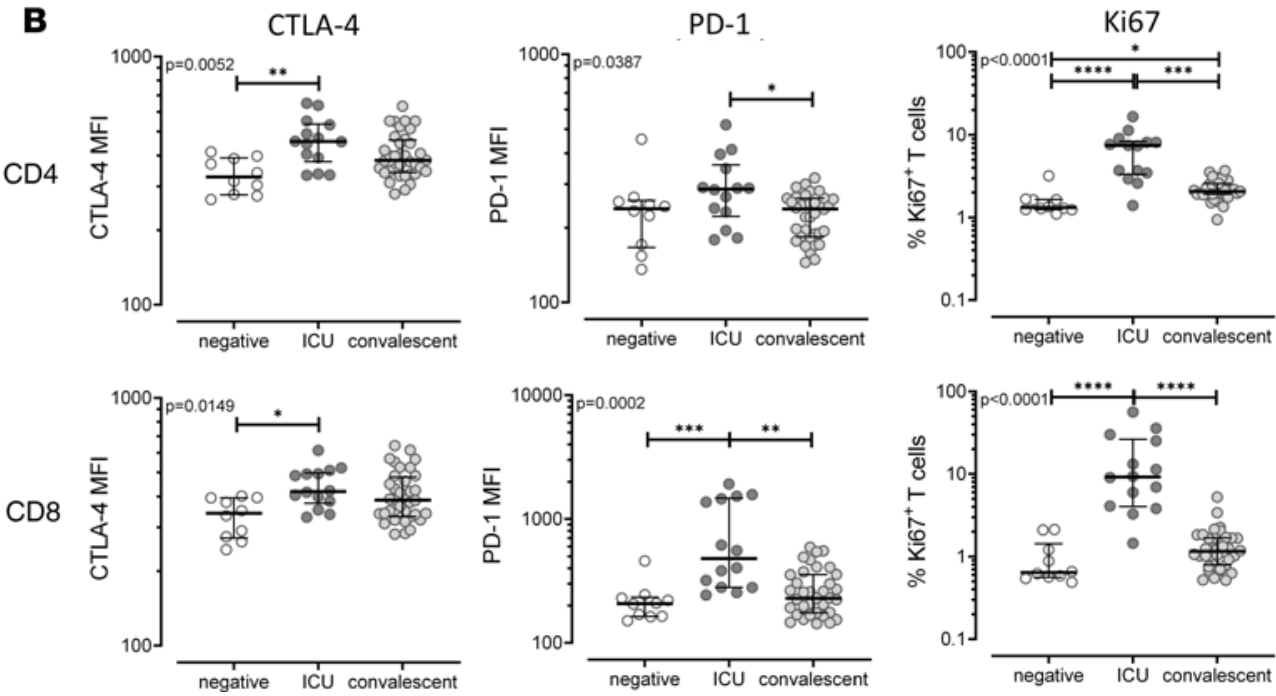

Figure 4. Altered characteristics of global CD4 ${ }^{+}$and $C D 8^{+} T$ cells in patients with severe COVID-19. (A) Representative contour plots showing expression of CTLA-4 and PD-1 and intranuclear Ki67 expression of unstimulated total CD4 ${ }^{+}$ and $C D 8^{+} T$ cells from an ICU patient and a convalescent individual. Because cells showed a continuum in the expression of CTLA- 4 and PD-1, cell surface expression levels of CTLA- 4 and PD- 1 were expressed as MFI. Numbers indicate expression levels (MFI) of CTLA-4 and PD-1 and percentage of Ki67 ${ }^{+}$cells among total CD4 ${ }^{+}$and CD8 ${ }^{+}$T cells. (B) Results were compared among SARS-CoV-2-negative individuals (negative, $n=10$ ), patients with severe COVID-19 (ICU, $n=14$ ), and convalescent patients $(n=36)$. Bars represent medians with IQRs. Differences between the groups were calculated using Kruskal-Wallis test and Dunn's posttest. ${ }^{*} P<0.05,{ }^{* *} P<0.01$, ${ }^{* *} P<0.001$, ${ }^{* * *} P<0.0001$.

individuals who recovered from mild disease that could be managed in an outpatient setting. Both groups were analyzed at the same time after onset of COVID-19 symptoms. As main findings, we show that patients with severe disease had high levels of SARS-CoV-2-specific CD4 ${ }^{+}$and CD8 ${ }^{+} \mathrm{T}$ cells as well as high titers of specific IgG and IgA antibodies as compared with convalescent individuals, where levels were significantly lower. However, SARS-CoV-2-specific T cells in severe cases had a restricted cytokine expression profile with fewer multifunctional cells and strongly expressed CTLA-4 as a hallmark of T cells in the contraction phase of an immune response after active encounter with the virus. In contrast, convalescent individuals who had recovered from mild or moderate disease had lower levels of SARS-CoV-2-specific humoral and cellular immunity, and antigen-specific $\mathrm{T}$ cells showed fewer signs of functional alterations. Finally, differences between the infected patient groups were also found for major lymphocyte subpopulations, such as $\mathrm{B}$ cells, NK cells, Tregs, and $\mathrm{CD} 4^{+}$and $\mathrm{CD} 8^{+} \mathrm{T}$ cells. Apart from severe lymphopenia, $\mathrm{CD} 4^{+}$ and $\mathrm{CD}^{+} \mathrm{T}$ cells from patients with severe COVID-19 exhibited increased expression of CTLA-4 and PD-1 and a high expression of Ki67 as a marker for recent proliferation. In addition, the percentage of cells responding after polyclonal stimulation was lower and restricted in functionality. In contrast, lymphocyte characteristics from convalescent individuals were similar as in noninfected controls. Taken together, this indicates that the severity of clinical disease in patients with COVID-19 is not only associated with prominent changes in the innate immune system but also characterized by a marked alteration of adaptive humoral and cellular immunity that includes both SARS-CoV-2-specific and global $\mathrm{T}$ cell function. 
A
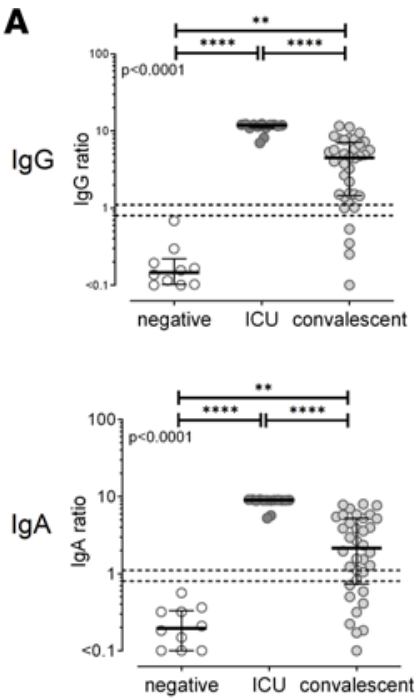

B

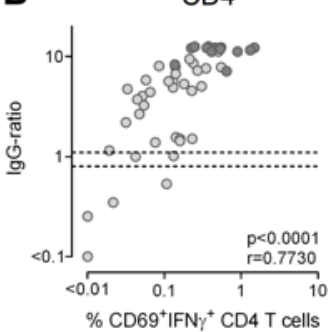

CD8

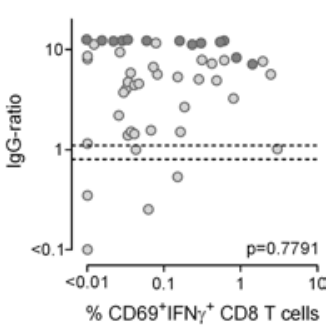

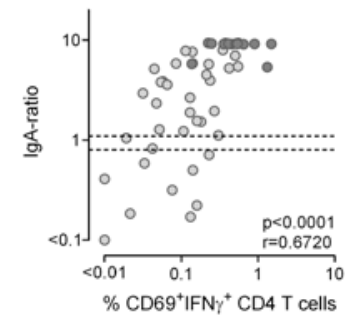

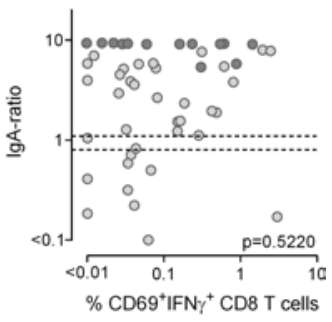

C
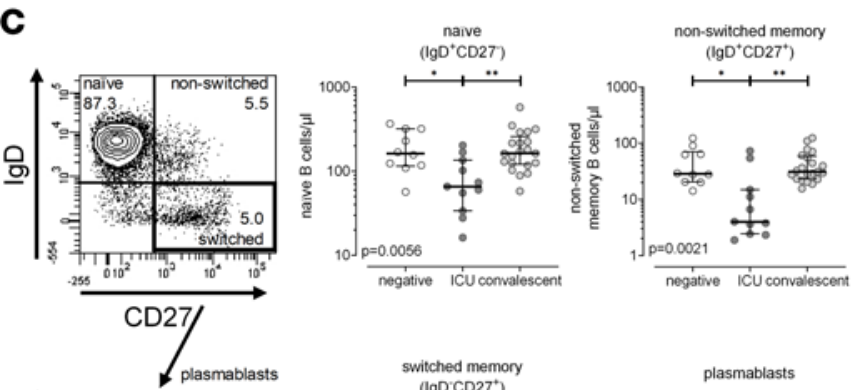

D
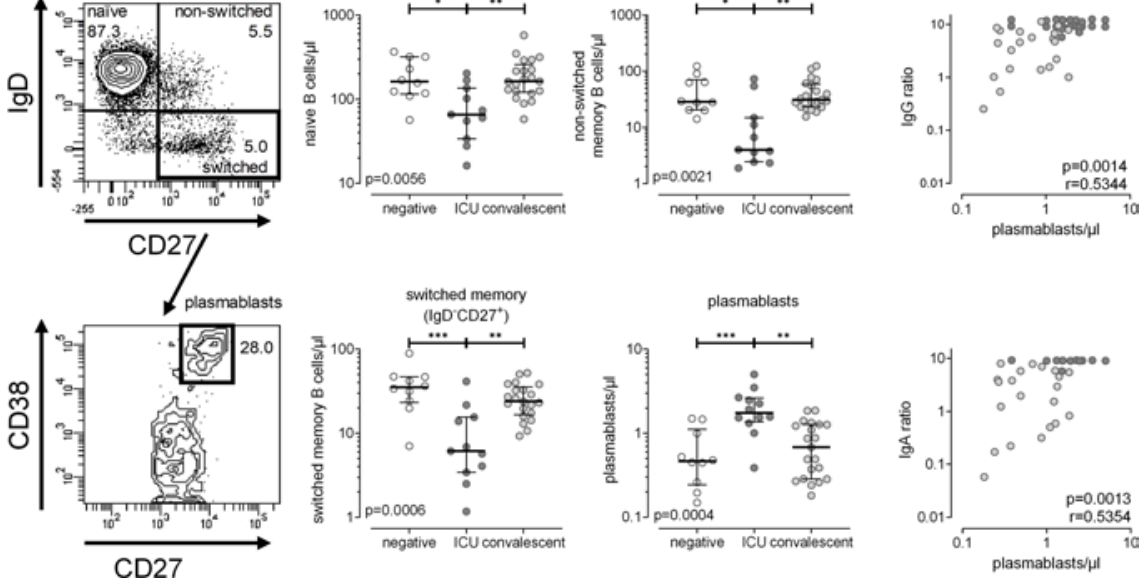

Figure 5. Strong correlation of SARS-CoV-2-specific $\mathrm{CD4}^{+} \mathrm{T}$ cell levels with specific IgG and IgA antibodies and plasmablasts. (A) Levels of SARS-CoV-2-specific IgG and IgA were compared among SARS-CoV-2-negative individuals (negative, $n=10$ ), patients with severe COVID-19 (ICU, $n=14$ ), and convalescent patients $(n=36)$. (B) Correlation between levels of SARS-CoV-2-specific IgG or IgA with frequencies of SARS-CoV-2-specific CD69+IFN- $\gamma^{+}$CD4 $4^{+}$or CD8 ${ }^{+}$T cells expressed in patients with SARS-CoV-2. (C) Representative contour plots of a 64-year-old hospitalized patient showing the differentiation status of $B$ cells characterized by surface expression of IgD and CD27, with plasmablasts identified among switched memory B cells by additional staining of CD38. Numbers of B cell subpopulations and plasmablasts were compared between groups, and (D) plasmablasts were correlated with levels of SARS-CoV-2-specific IgC and IgA. Antibody levels were determined semiquantitatively by dividing the optical density of an individual sample by that of a positive control serum. Bars in $\mathbf{A}$ and $\mathbf{C}$ represent medians with IQRs. Differences between the groups were calculated using Kruskal-Wallis test and Dunn's posttest. ${ }^{*} P<0.05,{ }^{* *} P<0.01,{ }^{* *} P<0.001$, ${ }^{* * *} P<0.0001$. Correlations in $\mathbf{B}$ and $\mathbf{D}$ were analyzed according to Spearman. Dotted lines indicate detection limits for IgG and IgA, indicating negative, intermediate, and positive levels, respectively, as per manufacturer's instructions.

Up to now, only few studies have described SARS-CoV-2-specific T cells in patients with COVID-19 $(7-11,22)$. With results from our study, key characteristics of SARS-CoV-2-specific T cells emerge. SARSCoV-2-reactive $\mathrm{T}$ cells exhibit immediate effector function with proliferative potential, and expression of IFN- $\gamma$, IL-2, and TNF- $\alpha$, which suggests a Th1 phenotype. This is supported by results from supernatants of stimulated peripheral blood mononuclear cells showing detectable IFN- $\gamma$, IL-2, and TNF- $\alpha$ and low levels of IL-5, IL-13, IL-9, IL-10, and IL-22 (7, 11). Reactive T cells exist among both CD4 ${ }^{+}$and CD8 ${ }^{+}$ $\mathrm{T}$ cells, and $\mathrm{CD} 8^{+} \mathrm{T}$ cells were able to produce effector molecules such as granzyme $\mathrm{B}$, and evidence of perforin and CD107a expression was recently found (10). In line with other reports $(8,10,11)$, SARS$\mathrm{CoV}-2-$ specific $\mathrm{CD} 4^{+} \mathrm{T}$ cell levels were higher than those of $\mathrm{CD}^{+} \mathrm{T}$ cells. Unlike $\mathrm{CD} 4^{+} \mathrm{T}$ cells, specific 
$\mathrm{CD}^{+} \mathrm{T}$ cell levels inversely correlated with time after onset of symptoms, which may reflect higher stability of $\mathrm{CD}^{+} \mathrm{T}$ cells. Alternatively, antigen-specific $\mathrm{CD} 8^{+} \mathrm{T}$ cells might have been recruited to the lungs as the site of massive SARS-CoV-2 replication because signatures for clonally expanded $\mathrm{CD} 8^{+} \mathrm{T}$ cells were found in bronchoalveolar lavage samples of patients with SARS-CoV-2-associated lung disease (23). Previous studies show that SARS-CoV-2-specific T cell levels differ in infected and noninfected individuals (7-11, 22). Our results suggest that SARS-CoV-2-specific $C D 4^{+} \mathrm{T}$ cells allowed for a better distinction not only of noninfected and infected individuals but also of patients with different severity of disease. This distinction may further be improved using immunodominant peptides for stimulation. So far, a relative immunodominance of the spike protein has been described $(8,11,22)$. This was also observed in our study, but the 4 viral structural proteins differed in their ability to induce specific immunity among $\mathrm{CD} 4^{+}$and $\mathrm{CD} 8^{+} \mathrm{T}$ cells. The VEMP protein elicited hardly any reactivity, which may be related to its small size and its relatively low abundance in the virus particle (24). Reactive $\mathrm{CD} 4^{+} \mathrm{T}$ cells were found toward all other proteins with a dominance of the spike and the VME1 proteins. Interestingly, apart from the N-terminal portion of the spike protein, $\mathrm{CD} 8^{+} \mathrm{T}$ cells showed pronounced reactivity toward the NCAP protein. NCAP may be more readily processed to be presented in $\mathrm{MHC}$ class I molecules because of its predominant localization in the cytoplasm, whereas all other membrane proteins are directly assembled in the ER membrane (25).

It was striking that patients with severe courses of disease had significantly higher levels of both SARSCoV-2-specific antibodies and T cells as compared with convalescent patients, which is in line with recent observations (10). Because all analyses were performed in a short time frame after onset of symptoms, we consider it unlikely that antibody and $\mathrm{T}$ cell levels in convalescent individuals had been similarly high during active viral replication and had decreased after successful control of infection. Instead, the levels of specific humoral and cellular immunity needed to control viral replication may be directly related to the viral load during primary infection. Thus, patients with a severe course may have required induction of higher levels of specific immunity. Whether this may be due to potentially higher viral load or prolonged periods of active viral replication needs further study with regular sampling. So far it is known that infection efficiency is high in nasal epithelial cells of the upper airways and decreases in epithelial cells of the lower respiratory tract along an angiotensin converting enzyme 2 receptor gradient (26). Therefore, viral replication may remain restricted to the upper airway in the majority of infected individuals with mild symptoms. Further seeding of virus to the lung may be favored by high viral load in the upper airways with subsequent microaspiration events that are more frequent in patients at risk for severe courses of COVID-19, such as elderly people or individuals with diabetes or obesity. Thus, lower viral load with local restriction to the upper airways may require less pronounced specific immunity as compared with higher viral load and/or further dissemination of the virus to the lower respiratory tract. This may be supported by our observation that SARS-CoV-2specific $\mathrm{CD}^{+} \mathrm{T}$ cell levels showed significant differences among convalescent individuals with or without symptoms of the lower respiratory tract (cough and dyspnea) $(P=0.015)$. The induction of specific immunity may further be modulated by preexisting cross-reactive immunity against common cold coronaviruses. This is illustrated by influenza vaccine studies, where preexisting immunity against influenza is associated with a less pronounced induction of vaccine-specific immunity as compared with influenza-naive subjects $(27,28)$. Evidence for cross-reactive immunity also exists among coronaviruses. In our study, very low levels of SARS-CoV-2-reactive T cells were in part detectable among control subjects without SARS-CoV-2 infection. However, as shown in recent studies using longer stimulation times, evidence for cross-reactive $\mathrm{T}$ cells is found in $20 \%$ to up to $50 \%$ of noninfected controls (8-11).

Based on a variety of clinically relevant pathogens, the quantity and the characteristics of antigenspecific $\mathrm{T}$ cells have been shown to differ in relation to the pathogen activity in the context of primary infections or reactivations. As exemplified for immunity against cytomegalovirus, varicella zoster virus, HIV, or mycobacteria, $\mathrm{T}$ cells induced by primary infection or reactivation during active encounter with the pathogen show a low percentage of multifunctional cells and increased expression of inhibitory surface receptors such as CTLA-4 or PD-1, whereas the expression of these molecules decreases with successful control of the pathogen $(15-18,21,29)$. In this respect, the lower CTLA-4 expression levels on SARS-CoV-2-specific T cells of convalescent individuals are compatible with successful viral control, whereas the increased expression of CTLA-4 on SARS-CoV-2-specific T cells in patients with severe disease may result from a prolonged and more intense encounter with the virus. Consistent with primary induction, specific $\mathrm{T}$ cells had a restricted cytokine pattern with a low percentage of multifunctional cells and a relative dominance of single or dual cytokine-producing cells expressing IL-2, which is different from reactivations, where the 
loss in multifunctional cells is associated with a shift toward cells exclusively expressing IFN- $\gamma(18,30)$. Although this functional profile of SARS-CoV-2-specific T cells in patients with severe disease has several characteristics of an exhausted phenotype found in patients with symptomatic disease in the context of chronic infections and/or reactivations, exhaustion is frequently associated with a quantitative decrease in specific $\mathrm{T}$ cells $(15,17)$. In contrast, our patients were able to mount a strong adaptive $\mathrm{T}$ cell response with proliferative potential, and the majority of patients achieved control of viral replication. Therefore, the high expression levels of CTLA-4 and the restricted functionality may reflect a physiological contraction mechanism to downregulate immune hyperactivation and specific immunity after its strong induction and to compensate for excessive immunopathology in the lung. This process appears to have notable effects on lymphocyte subpopulations and their functional characteristics in general, which show the same pattern of inhibitory surface receptors and functional restriction and thereby may account for an increased susceptibility for other opportunistic infections in patients with severe COVID-19 (31, 32).

As with SARS-CoV-2-specific T cells, specific antibody responses were also highest in patients with severe disease. Interestingly, despite severe B cell lymphopenia that affected all major subpopulations, the increased antibody levels showed a direct correlation with the number of circulating plasmablasts, which were significantly higher than in convalescent patients and noninfected controls. Because high antibody responses were shown to correlate with neutralization capacity, this may directly contribute to viral clearance $(13,14,33)$. However, given the association with disease severity, further studies should address whether antibodies may also contribute antibody-dependent enhancement of viral entry into Fc receptorexpressing cells, such as macrophages, thereby leading to increased inflammation and lung injury (34).

Our study is limited by a low sample size, especially regarding some parameters that were analyzed in a subset of patients only. Nevertheless, differences in general as well as antigen-specific immunity between the 2 patient groups are very pronounced and correlate well with the severity of the disease. Moreover, we did not perform any longitudinal analyses of specific $\mathrm{T}$ cells and antibodies to evaluate whether the levels of specific immunity during primary infection determined stability and protection in the long term. Data on SARS-CoV-1-specific immunity indicated that both antibodies and T cells were detectable for several years, with highest stability in patients with more severe disease $(35,36)$. Similar studies with larger sample sizes are needed to evaluate whether the more pronounced immunity in patients with severe COVID-19 may result in higher stability after recovery and better protection from reinfection with SARS-CoV-2 in the long term.

Knowledge gained from this study may have implications for vaccine design and therapeutic management. Our study revealed an immunodominance of specific $\mathrm{T}$ cells toward the spike protein as the main vaccine target. In addition, other viral proteins may represent promising antigens to achieve a broad vaccine-induced $\mathrm{T}$ cell response comparable to natural infection. Up to now, the role of immunosuppressive drugs for treatment of COVID-19 has been controversially discussed (37). Our results show that patients with severe disease mount a particularly strong cellular and humoral immune response. Although this immune response seems to be efficient in controlling viremia, contraction is required to prevent immunopathology associated with a hyperactive immune system. It is therefore tempting to speculate that immunosuppressive drugs are harmful when given in the induction phase but may have particular benefit in the contraction phase of the immune response. Data emerging from the RECOVERY Trial indeed provide first evidence for a particular survival benefit of dexamethasone treatment in ventilated patients with severe disease (38).

\section{Methods}

Study design and patient population. Patients who were hospitalized with PCR-confirmed COVID-19 (ICU patients) and patients with a milder course of disease in an outpatient setting were recruited, who had been matched with ICU patients according to the time since onset of clinical symptoms. In addition, individuals without evidence for infection with SARS-CoV-2 were tested as negative controls. ICU patients were recruited within the CORSAAR study, a cohort study on patients with COVID-19. Information on clinical symptoms was derived from patient charts or collected based on a questionnaire. Blood samples $(4.7 \mathrm{~mL})$ were collected in lithium heparin-containing tubes, and all analyses of antigen-specific $\mathrm{T}$ cells and lymphocyte subpopulations were carried out within 24 hours. Antibody testing was performed using frozen plasma samples.

Quantitation of lymphocyte populations. Quantitation and characterization of lymphocyte subpopulations were performed on $100 \mu \mathrm{L}$ of heparinized whole blood as described before (39) using monoclonal antibodies 
against CD3 (clone SK7), CD4 (clone SK3), CD8 (clones RPA-T8 and SK1), CD16 (clone 3G8), CD19 (clone HIB19), CD25 (clone M-A251), CD27 (clone L128), CD38 (clone HB7), CD56 (clone B159), CD127 (clone eBioRDR5, eBioscience, Thermo Fisher Scientific), CTLA-4 (clone BNI3), IgD (clone IA6-2), and PD-1 (clone MIH4, all from BD Biosciences). For samples that included anti-CD27 and anti-IgD, whole blood was washed with medium (RPMI) before staining to remove soluble CD27 and IgD. After 25 minutes of incubation, samples were treated with lysing solution (BD Biosciences). Thereafter, cells were washed with FACS buffer (PBS, $5 \%$ filtered FCS, $0.5 \%$ bovine serum albumin, $0.07 \% \mathrm{NaN}_{3}$ ) and analyzed using flow cytometry (BD FACSCanto II) and FACSDiva V6.1.3 software (BD Biosciences). Gating strategies for each staining procedure are provided in Supplemental Figure 5. Intranuclear staining of Ki67 (clone B56) was performed using the Foxp3/transcription factor staining buffer set according to the manufacturer's instructions (eBioscience, Thermo Fisher Scientific). Differentiation status of $\mathrm{CD} 19^{+} \mathrm{B}$ cells was assessed using antibodies against IgD and CD27. Plasmablasts were identified among switched memory B cells by additional staining of CD38. In addition, T cells were analyzed for expression of PD-1 and CTLA-4. Differential blood counts were used to calculate absolute lymphocyte numbers. $\mathrm{CD}^{+}$and $\mathrm{CD} 8^{+} \mathrm{T}$ cells were quantified among $\mathrm{CD}^{+} \mathrm{T}$ cells and these among lymphocytes. NK cells were identified using antibodies against CD3, CD16, and CD56 and quantified as CD3 ${ }^{-} \mathrm{CD} 16^{+} / \mathrm{CD} 56^{+}$lymphocytes. Tregs were identified among $\mathrm{CD}^{+} \mathrm{T}$ cells by high expression of CD25 and low CD127 expression. Detailed information on antibodies for flow cytometric stainings is given in Supplemental Table 1.

Stimulation assays. Whole-blood samples were stimulated with overlapping peptide pools spanning the SARS-CoV-2 spike protein (spike vial 1, N-terminal receptor binding domain; and spike vial 2, C-terminal portion including the transmembrane domain), the NCAP protein, the membrane protein VME1, and the envelope small membrane protein VEMP $(1 \mu \mathrm{g} / \mathrm{mL}$ each; JPT, Supplemental Table 2$)$ to induce antigen-specific activation and cytokine induction as described previously (17). As a negative control, samples were treated with the diluent DMSO. Cells were stimulated with $2.5 \mu \mathrm{g} / \mathrm{mL}$ SEB (MilliporeSigma) to assess general characteristics of polyclonally stimulated T cells. Stimulation was performed from whole blood in the presence of costimulatory antibodies against CD28 and CD49d ( $1 \mu \mathrm{g} / \mathrm{mL}$ each) for 6 hours, with $10 \mu \mathrm{g} / \mathrm{mL}$ brefeldin A added after 2 hours of incubation. After 6 hours, samples were treated with 20 mM EDTA for 15 minutes; thereafter, cells were fixed using BD lysing solution, and stimulated cells were immunostained using anti-CD4 (clone SK3), anti-CD69 (clone L78), anti-IFN- $\gamma$ (clone 4S.B3), anti-IL-2 (clone MQ1-17H12), anti-TNF- $\alpha$ (clone MAb11), anti-PD-1 (clone MIH4), anti-CTLA-4 (clone BNI3), anti-Ki67 (clone B56), or anti-granzyme B (clone GB11). All stainings except for PD-1 were performed after fixation. Ki67 staining was performed using the Foxp3/transcription factor staining buffer set as described above. Cells were analyzed using flow cytometry. Gating strategies are provided in Supplemental Figures 6 and 7. A schematic representation for cytokine profiling after stimulation with SARS-CoV-2 peptides and SEB is shown in Supplemental Figure 8.

Analysis of SARS-CoV-2-specific antibodies. SARS-CoV-2-specific antibodies were quantified from heparinized plasma samples using an IgG and IgA assay coated with recombinant S1 domain of SARS-CoV-2 spike protein antigen according to the manufacturer's instructions (Euroimmun). Antibody levels are expressed as ratios that are defined as the extinction of the patient sample divided by the extinction of a calibrator serum. Ratios less than 0.8 were scored negative, ratios between 0.8 and 1.1 were scored intermediate, and ratios of or greater than 1.1 were scored positive.

Statistics. Statistical analysis was carried out using GraphPad Prism 8.0 software using 2-tailed $t$ tests. An unpaired nonparametric Kruskal-Wallis test with Dunn's posttest was used to analyze differences for lymphocyte subpopulations, T cell and antibody levels, as well as PD-1, CTLA-4, and Ki67 of total T cells among the 3 groups. Mann-Whitney $U$ test was performed to compare nonparametric data between 2 groups (time since onset of symptoms and expression of CTLA-4, PD-1, Ki67, and granzyme B of specific $\mathrm{T}$ cells). Data with normal distribution were analyzed using unpaired $t$ test (cytokine expression) or 1-way ANOVA test (age). Differences in sex were analyzed using $\chi^{2}$ test. Correlations between $\mathrm{T}$ cell levels, antibody titers, plasmablasts, and time from onset of symptoms were analyzed according to Spearman. A $P$ value of less than 0.05 was considered statistically significant.

Study approval. The study was approved by the ethics committee of the Ärztekammer des Saarlandes (references $76 / 20 ; 162 / 20$ ), and all individuals or their legal representatives gave written informed consent.

\section{Author contributions}

DS, TS, US, SS, BCG, SLB, and MS designed the study; DS, TS, US, and MS designed the experiments. DS, VK, and TS performed experiments; SS, BCG, PML, HW, RB, JM, and HE contributed to study design, 
patient recruitment, and clinical data acquisition. DS, TS, US, and MS supervised all parts of the study, performed analyses, and wrote the manuscript. All authors approved the final version of the manuscript.

\section{Acknowledgments}

The authors thank Candida Guckelmus and Rebecca Urschel for excellent technical assistance. The authors also thank all participants in this study who contributed to the gain in knowledge from this project. The study was supported by institutional funds to MS and in part by grants of Saarland University (to MS and $\mathrm{RB})$, the State of Saarland, and the Rolf M. Schwiete Stiftung to RB.

Address correspondence to: Martina Sester, Saarland University, Department of Transplant and Infection Immunology, Institutes of Infection Medicine, Building 47, Kirrberger Straße, D-66421 Homburg, Germany. Phone: 49.6841.1623557; Email: martina.sester@uks.eu.

1. Huang C, et al. Clinical features of patients infected with 2019 novel coronavirus in Wuhan, China. Lancet. 2020;395(10223):497-506.

2. Guan WJ, et al. Clinical characteristics of coronavirus disease 2019 in China. N Engl J Med. 2020;382(18):1708-1720.

3. Wang F, et al. Characteristics of peripheral lymphocyte subset alteration in COVID-19 pneumonia. J Infect Dis. 2020;221(11):1762-1769.

4. Chen G, et al. Clinical and immunological features of severe and moderate coronavirus disease 2019. J Clin Invest. 2020;130(5):2620-2629.

5. Wang F, et al. The laboratory tests and host immunity of COVID-19 patients with different severity of illness. JCI Insight. 2020;5(10):137799.

6. Zheng HY, et al. Elevated exhaustion levels and reduced functional diversity of T cells in peripheral blood may predict severe progression in COVID-19 patients. Cell Mol Immunol. 2020;17(5):541-543.

7. Ni L, et al. Detection of SARS-CoV-2-specific humoral and cellular immunity in COVID-19 convalescent individuals. Immunity. 2020;52(6):971-977.e3.

8. Grifoni A, et al. Targets of T cell responses to SARS-CoV-2 coronavirus in humans with COVID-19 disease and unexposed individuals. Cell. 2020;181(7):1489-1501.e15.

9. Le Bert N, et al. SARS-CoV-2-specific T cell immunity in cases of COVID-19 and SARS, and uninfected controls. Nature. 2020;584(7821):457-462.

10. Sekine $\mathrm{T}$, et al. Robust $\mathrm{T}$ cell immunity in convalescent individuals with asymptomatic or mild COVID-19. Cell. 2020;5(49):eabd6160.

11. Weiskopf D, et al. Phenotype and kinetics of SARS-CoV-2-specific T cells in COVID-19 patients with acute respiratory distress syndrome. Sci Immunol. 2020;5(48):eabd2071.

12. Guo L, et al. Profiling early humoral response to diagnose novel coronavirus disease (COVID-19). Clin Infect Dis. 2020;71(15):778-785

13. Wölfel R, et al. Virological assessment of hospitalized patients with COVID-2019. Nature. 2020;581(7809):465-469.

14. Okba NMA, et al. Severe acute respiratory syndrome coronavirus 2-specific antibody responses in coronavirus disease patients. Emerging Infect Dis. 2020;26(7):1478-1488.

15. Sester M, Leboeuf C, Schmidt T, Hirsch HH. The "ABC" of virus-specific T cell immunity in solid organ transplantation. Am J Transplant. 2016;16(6):1697-1706.

16. Schub D, et al. CTLA-4-expression on VZV-specific T cells in CSF and blood is specifically increased in patients with VZV related central nervous system infections. Eur J Immunol. 2018;48(1):151-160.

17. Sester U, Presser D, Dirks J, Gärtner BC, Köhler H, Sester M. PD-1 expression and IL-2 loss of cytomegalovirus- specific T cells correlates with viremia and reversible functional anergy. Am J Transplant. 2008;8(7):1486-1497.

18. Schub D, et al. Altered phenotype and functionality of varicella zoster virus-specific cellular immunity in individuals with active infection. J Infect Dis. 2015;211(4):600-612.

19. Schub D, et al. Assay for improved detection of antigen-specific immune cells from extrasanguinous fluids. Eur J Immunol. 2018;48(8):1412-1414.

20. Schmidt T, et al. BK polyomavirus-specific cellular immune responses are age-dependent and strongly correlate with phases of virus replication. Am J Transplant. 2014;14(6):1334-1345

21. Sester U, et al. Whole-blood flow-cytometric analysis of antigen-specific CD4 T-cell cytokine profiles distinguishes active tuberculosis from non-active states. PLoS One. 2011;6(3):e17813.

22. Braun J, et al. SARS-CoV-2-reactive T cells in healthy donors and patients with COVID-19 [published online July 29, 2020] Nature. https://doi.org/10.1038/s41586-020-2598-9.

23. Liao M, et al. Single-cell landscape of bronchoalveolar immune cells in patients with COVID-19. Nat Med. 2020;26(6):842-844.

24. Naqvi AAT, et al. Insights into SARS-CoV-2 genome, structure, evolution, pathogenesis and therapies: structural genomics approach. Biochim Biophys Acta Mol Basis Dis. 2020;1866(10):165878.

25. de Wilde AH, Snijder EJ, Kikkert M, van Hemert MJ. Host factors in coronavirus replication. Curr Top Microbiol Immunol. 2018;419:1-42.

26. Hou YJ, et al. SARS-CoV-2 reverse genetics reveals a variable infection gradient in the respiratory tract. Cell. 2020;182(2):429-446.e14.

27. Sester U, Schmidt T, Kuhlmann MK, Gärtner BC, Uhlmann-Schiffler H, Sester M. Serial influenza-vaccination reveals impaired maintenance of specific T-cell memory in patients with end-stage renal failure. Vaccine. 2013;31(38):4111-4120. 
28. Schmidt T, et al. CD4+ T-cell immunity after pandemic influenza vaccination cross-reacts with seasonal antigens and functionally differs from active influenza infection. Eur J Immunol. 2012;42(7):1755-1766.

29. Barber DL, et al. Restoring function in exhausted CD8 T cells during chronic viral infection. Nature. 2006;439(7077):682-687.

30. Elsäßer J, et al. Antigen-specific CD4 T cells are induced after intravesical BCG-instillation therapy in patients with bladder cancer and show similar cytokine profiles as in active tuberculosis. PLoS One. 2013;8(9):e69892.

31. Chen N, et al. Epidemiological and clinical characteristics of 99 cases of 2019 novel coronavirus pneumonia in Wuhan, China: a descriptive study. Lancet. 2020;395(10223):507-513.

32. Rawson TM, et al. Bacterial and fungal co-infection in individuals with coronavirus: a rapid review to support COVID-19 antimicrobial prescribing [published online May 2, 2020]. Clin Infect Dis. https://doi.org/10.1093/cid/ciaa530.

33. Zhao J, et al. Antibody responses to SARS-CoV-2 in patients of novel coronavirus disease 2019 [published online May 28 , 2020]. Clin Infect Dis. https://doi.org/10.1093/cid/ciaa344.

34. Taylor A, Foo SS, Bruzzone R, Dinh LV, King NJ, Mahalingam S. Fc receptors in antibody-dependent enhancement of viral infections. Immunol Rev. 2015;268(1):340-364.

35. Cao WC, Liu W, Zhang PH, Zhang F, Richardus JH. Disappearance of antibodies to SARS-associated coronavirus after recovery. N Engl J Med. 2007;357(11):1162-1163.

36. Tang F, et al. Lack of peripheral memory B cell responses in recovered patients with severe acute respiratory syndrome: a six-year follow-up study. J Immunol. 2011;186(12):7264-7268.

37. Vabret N, et al. Immunology of COVID-19: current state of the science. Immunity. 2020;52(6):910-941.

38. RECOVERY Collaborative Group, et al. Dexamethasone in hospitalized patients with Covid-19 - preliminary report [published online July 17, 2020]. N Engl J Med. https://doi.org/10.1056/NEJMoa2021436.

39. Schoch J, et al. Quantitative, phenotypical, and functional characterization of cellular immunity in children and adolescents with down syndrome. J Infect Dis. 2017;215(10):1619-1628. 